
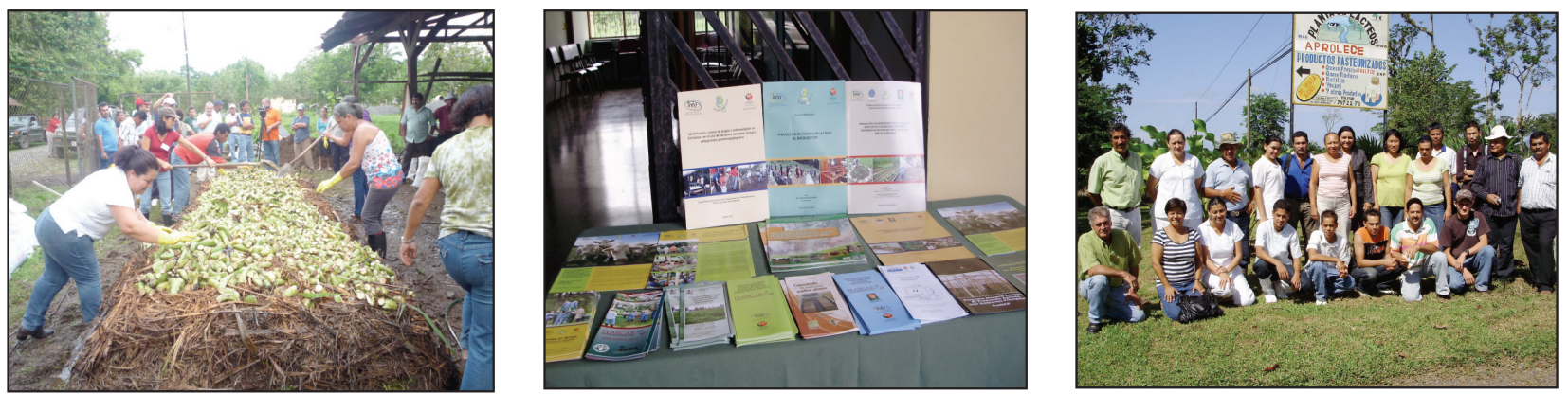

\section{Resultados y Logros del Proyecto}

- Se logró el intercambio de las siguientes tecnologías amigables con el ambiente entre Costa Rica y Bhutan: Ensilaje, biodogestores, hidroponía, agricultura de bajos insumos, sistemas de fincas integradas, rescate de semillas locales, agricultura orgánica, mejoramiento genético en ganadería, industrialización de productos lácteos, sistemas sostenibles de producción de café, manejo de sistemas de raíces tropicales (yuca), manejo de recursos naturales, entre otros. En total se beneficiaron directamente 700 personas en Costa Rica y Bhutan.

- Se dispone de 40 servicios de información y comunicación en las Plataformas PLATICAR y VERCON.

- Se logró para Costa Rica la elaboración de 11 documentos en buenas prácticas agrícolas y materiales didácticos para la gestión de conocimiento, a continuación el detalle de los documentos publicados y que se han distribuido entre los beneficiarios del proyecto, universidades, ONG, instituciones del sector agropecuario en general. Se logró un tiraje de al menos 500 ejemplares de cada uno para un total de 5.000 ejemplares impresos y 500 ejemplares en formato digital. Documentos publicados:

- Manual: Agricultura Orgánica de Bajo Costo.

- Manual: Producción de diferente tipos de abonos, repelentes y fungicidas orgánicos. Experiencias de productores en la zona Sur de Costa Rica.
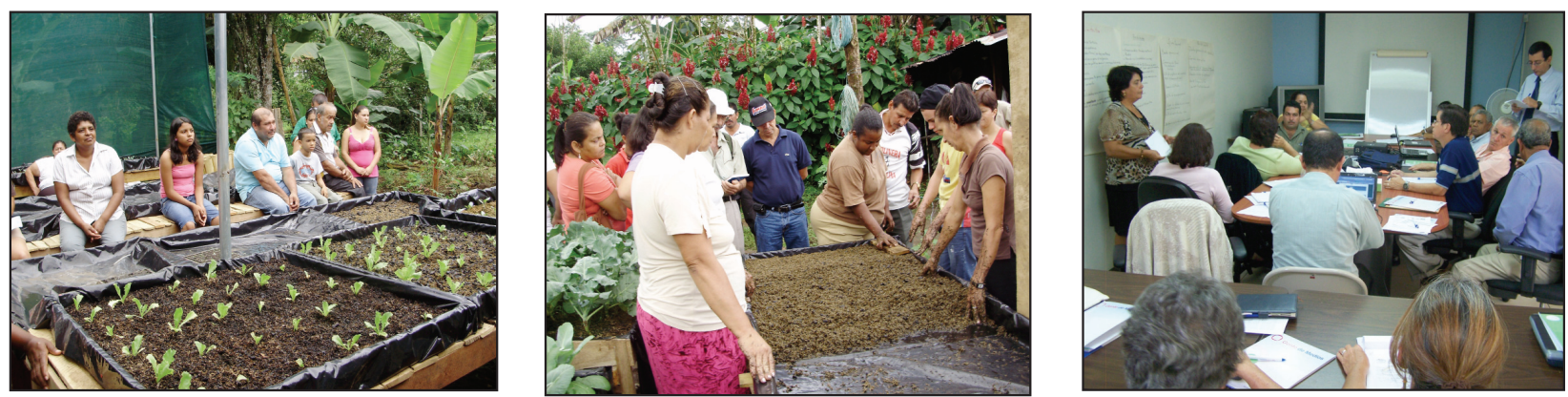

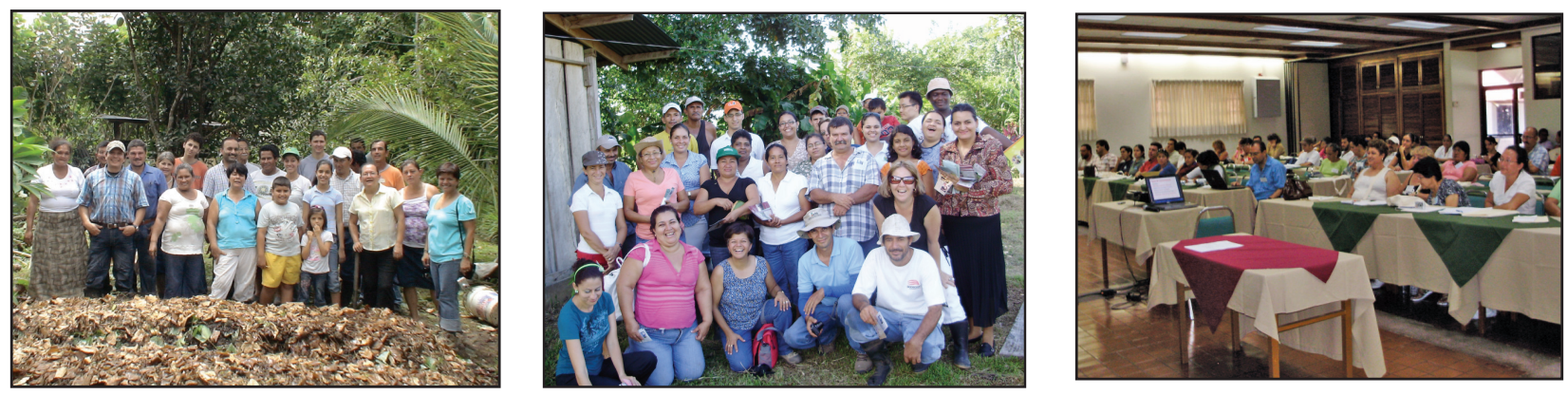

- Se apoyó en la capacitación de productores para el rescate de semillas locales en la Región Brunca del país y se dispone de una estrategia.

- Actualmente en el servicio INFOTECA del portal Web de PLATICAR se cuenta con más de 100 documentos generados por el INTA que están a disposición de todo público, de Costa Rica y de Bhutan.

- Actualmente se está desarrollando con el apoyo de Costa Rica, un servicio para poder sistematizar el "Proceso de mejoramiento genético en Bhutan", se está desarrollando para Bhutan y se trasladará y validará en Costa Rica también.

- Se logró democratizar el acceso a la información tecnológica por parte de productores, investigadores y extensionistas (500 personas que han dinamizado la información tecnológica).

- Se logró el desarrollo de capacidades en técnicos y profesionales (100 personas) en metodologías de comunicación, gestión de información. Gestión de conocimiento, mediación pedagógica, facilitación y gestores de conocimiento.

- Los logros en el marco de este proyecto han sido posibles gracias al trabajo coordinado con alianzas de: organizaciones de productores, universidades (UNED-EARTH-UCR), ONG'S (FICOSAFUNDAOSA), MINAET, Fundación Pro-Humano 21, Colegios Técnicos Agropecuarios, Ministerio de Agricultura y Ganadería,Municipalidades, Canales de Televisión local, entre otras.

- Productores, técnicos, extensionistas, investigadores y profesionales han participado en los procesos de capacitación y en procesos de Gestión de Conocimiento local: a) Gestión de Conocimiento Local en Ganadería Sostenible Finca Miguel Navarro Carranza y Familia; b) Gestión de Conocimiento Local en Agricultura Orgánica 10 fincas del Área de Conservación
Tortuguero (APOC); c) Gestión de conocimiento local en Agricultura de Bajo Costo 100 Productores de 25 comunidades Aledañas al Parque Nacional Tortuguero; d)Gestión de conocimiento local en Mediación Pedagógica en Finca Génesis, prácticas de control de plagas y producción orgánica; e) Gestión de conocimiento local en el Manejo y uso de las Técnicas de información y Comunicación Agropecuaria y Rural, 15 líderes de 12 comunidades aledañas al Parque Nacional Tortuguero y 5 profesionales del Centro Experimental Los Diamantes en Guápiles Pococí; f) Gestión de conocimiento local en el manejo de la computadora; g) Gestión de conocimiento local en Cultivos Hidropónicos 150 familias de 12 comunidades del Área de Conservación Tortuguero.

El valor agregado del proyecto fue consolidar ambas plataformas VERCON y PLATICAR y en el caso de Costa Rica, ampliar su área de cobertura e internacionalizarla, para poner a disposición del sector productivo nacional las opciones tecnológicas y buenas prácticas ambientales que fortalezcan los niveles de competitividad del sector agropecuario.

Ha habido una replicabilidad de las tecnologías, apropiación y ajuste a cada contexto ambiental y socio económico en cada país. Se logró la democratización del conocimiento, el cierre de brecha digital y la creación y dinamización de comunidades de práctica.

La tercera "Annual Global South-South Development Expo (GSSD Expo)" concluyó en Ginebra en noviembre 2010. Muy orgullosos nos sentimos los participantes de los proyectos de Costa Rica, Bhutan y Benin del Programa de Cooperación Sur-Sur por haber ganado el Premio 2010 como "Socios" y un reconocimiento especial por ser una de las soluciones más innovadoras en el Foro de Cambio Climático y Ambiente. 
